\title{
Rompesuelas. Toro de la Vega 2015
}

Keywords: Toro de la Vega; Maltrato animal; tradición; cultura

Se llama Rompesuelas, pesa aproximadamente 640 Kilos, ha vivido 6 años en la dehesa de los Herederos del Excelentísimo Sr. Conde de la Corte y morirá alanceado el próximo martes 15 de septiembre en el Torneo del Toro de la Vega que se celebra en Tordesillas, si, como es previsible, no consigue salir del recinto llamado "Campo de Honor", sino que alguno de los participantes consigue darle muerte, tras perseguirle y acosarle a pie y a caballo, armados con largas picas terminadas en una punta de lanza. En los últimos 20 años, sólo dos toros han conseguido salir indemnes.

El toro, al que hacen salir de los corrales y atravesar en estampida las calles del pueblo llenas de gente, lo que hace es correr despavorido cuando sale a campo abierto y tratar de encontrar refugio donde pueda, hasta que el cansancio y las heridas que le producen durante la carrera le hace desplomarse. Entonces sí, un lanzazo acaba con su último aliento y un Jurado examina quíen ha sido el ganador del trofeo, que

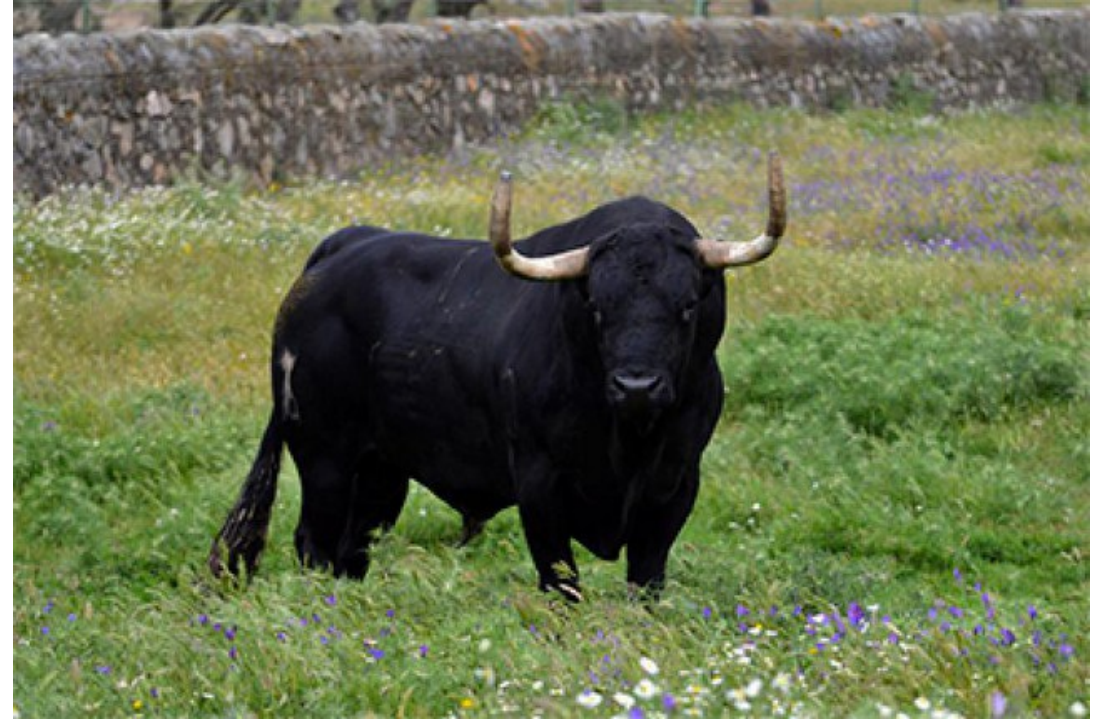
ostenta el honor de haber ajusticiado a un ser lleno de vida. Porque por mucho que lo revistan de nombres altisonantes en el Reglamento vigente desde el S.XIII (caballeros jinetes, torneantes, campo de honor, defensa, etc)[1], de lo que estamos hablando es de un espectáculo sangriento, que produce rechazo incluso a los aficionados a las corridas de toros y, por supuesto a toda una sociedad en España que cada año levanta la voz, de forma más fuerte y enérgica para que se prohíba lo que no dudo en calificar como barbarie sin justificación.

Los valores de la sociedad del S. XXI han cambiado respecto a los animales. Sí se puede afirmar que, lo que en la Edad Media podría parecer tolerable, hoy en día produce repulsa y no se corresponde con el progreso moral que, en este terreno del reconocimiento de los animales como seres a los que no se debe maltratar y mucho menos para divertir, es evidente. No hay más que ver, que son muchas las voces de ciudadanos corrientes y de personajes conocidos que, cada año, protestan por la celebración de este festejo cruel. Hoy no toleraríamos ejecuciones en la plaza pública, en día de mercado, con presencia incluso de niños, cuando éstas han sido usuales en todo el mundo occidental hasta bien entrado el S.XIX y aún persisten en algunos países orientales. Por lo tanto la sensibilidad social, los hábitos culturales, en definitiva, el progreso moral, incluye a día de hoy a los animales como último bastión de defensa de los más vulnerables.

Este año se anuncia la muerte de "Rompesuelas", en los carteles que promocionan el "Tradicional, Famoso y Único espectáculo taurino de la lidia del 'Toro de la Vega'". He transcrito la grafía del cártel, pues merece la pena detenerse en lo que se ofrece como valor intangible, por parte de los promotores de un acto de violencia legitimada contra un toro[2], que como todos los mamíferos, es un ser dotado de sensibilidad y capacidad de experimentar dolor[3], igual que la tenemos nosotros los humanos[4]. Se le mata de forma cruenta en nombre de la Tradición, de la Fama y de la singularidad del espectáculo. 
que la cultura y la ciencia experimentan, por ello el binomio Tradición-Cultura no significa que un acto (una norma, un hábito social, una ceremonia, un ritual), porque se repita de forma invariable, es inmune a la crítica[5]. De hecho el error está en considerar, como afirma Robert Hall, que "la cultura es un monolito de normas totalmente fijadas" que está fuera de una realidad palpable como es el progreso moral de la sociedad. Cuando en realidad "la cultura (cualquier cultura), es una mezcla de normas, opiniones, leyes (incluyendo algunas veces normas contradictorias) y el progreso moral es un proceso de cambios poco a poco"[6].

Respecto de la Fama, a la que alude el segundo incentivo del pretendido "festejo" de Tordesillas, no puede negarse que sí es famoso, pero dudo que lo sea para bien y que puedan enorgullecerse de ello los organizadores y los que apoyan la celebración ritual del acoso y derribo de un animal aturdido por el vocerío de unos torneantes armados y a caballo. Desde luego, este año hasta asociaciones de la seriedad y el prestigio de Humane Society International, han lanzado una campaña de recogida de firmas para solicitar a las autoridades que se ponga fín a una celebración que es una lacra para toda una sociedad. Sin olvidar la campaña "Rompe una lanza", que está alcanzando una gran difusión gracias al esfuerzo del PACMA.

En definitiva, es cierto que se trata de un espectáculo único. Un resto ancestral de violencia contra un animal indefenso. Pero, por ello mismo, debe desaparecer cuanto antes.

Este año en Sagunto, tras las multas y pronunciamientos judiciales de los más altos tribunales, ya no se han soltado al mar patos vivos, sino pelotas de goma. Hace años que ya no se tira la cabra desde el campanario de la Iglesia de Manganeses de la Polvorosa, ni la pava desde el campanario de Cazalilla de la Sierra, ni los quintos de Guarrate le cortan la cabeza a espada a los gallos colgados en la plaza del pueblo. Pero nuestro repertorio de tradiciones sangrientas contra los animales sigue siendo una vergüenza social y refleja una enorme desidia por parte de nuestros sucesivos Gobiernos, que se olvidan de que el poder de la compasión frente a los más débiles es un valor ético-social que redunda en beneficio de todos, sin exclusión. En los festejos y celebraciones religiosas de este verano[7] , con encierro incluido, han muerto ya 13 personas. Me pregunto, qué políticas públicas sostienen y justifican espectáculos de maltrato animal -con algo más que riesgo para la vida de los ciudadanos- y qué ciudadanos son los que quieren seguir sustentando tales espectáculos con sus impuestos. Yo, desde luego, no.

LA EDITORA

Teresa Giménez-Candela

Catedrática de Derecho Romano

Directora del Master en Derecho Animal y Sociedad Directora del SGR Grupo de Investigación ADS

Universitat Autònoma de Barcelona

Sígueme en Facebook: https://www.facebook.com/editora.da

[1] GIMÉNEZ-CANDELA, T., La aguja y la pica http://www.derechoanimal.info/eng/page/2378/the-needle-and-the-pike

[2] GIMÉNEZ-CANDELA, T., Ritos populares y violencia legítima, publicado originalmente el 16 de septiembre de 2008 en publico.es y reproducido actualmente

[3] GIMÉNEZ-CANDELA, T., Seres sintientes http://www.derechoanimal.info/eng/page/3142/sentient-beings;

[4] CAMPS I RABADÀ, J., La genética y la evolución confirman que los toros de lidia sienten dolor

[5] GIMÉNEZ-CANDELA, T., Tradición y Cultura crítica. A propósito del Toro de la Vega; Tradition and critical culture. About the Toro de la Vega

[6] HALL, Robert T. 2014. "Justificación de una metodología de la ética aplicada. Una glosa sobre la casuística", en Hall, Robert y José Salvador Arellano (Coords.). La Casuística: una metodología para la ética aplicada )Ciudad de México. Fontamara/UAQ)106.

[7] GIMÉNEZ-CANDELA, T., Santa crueldad 


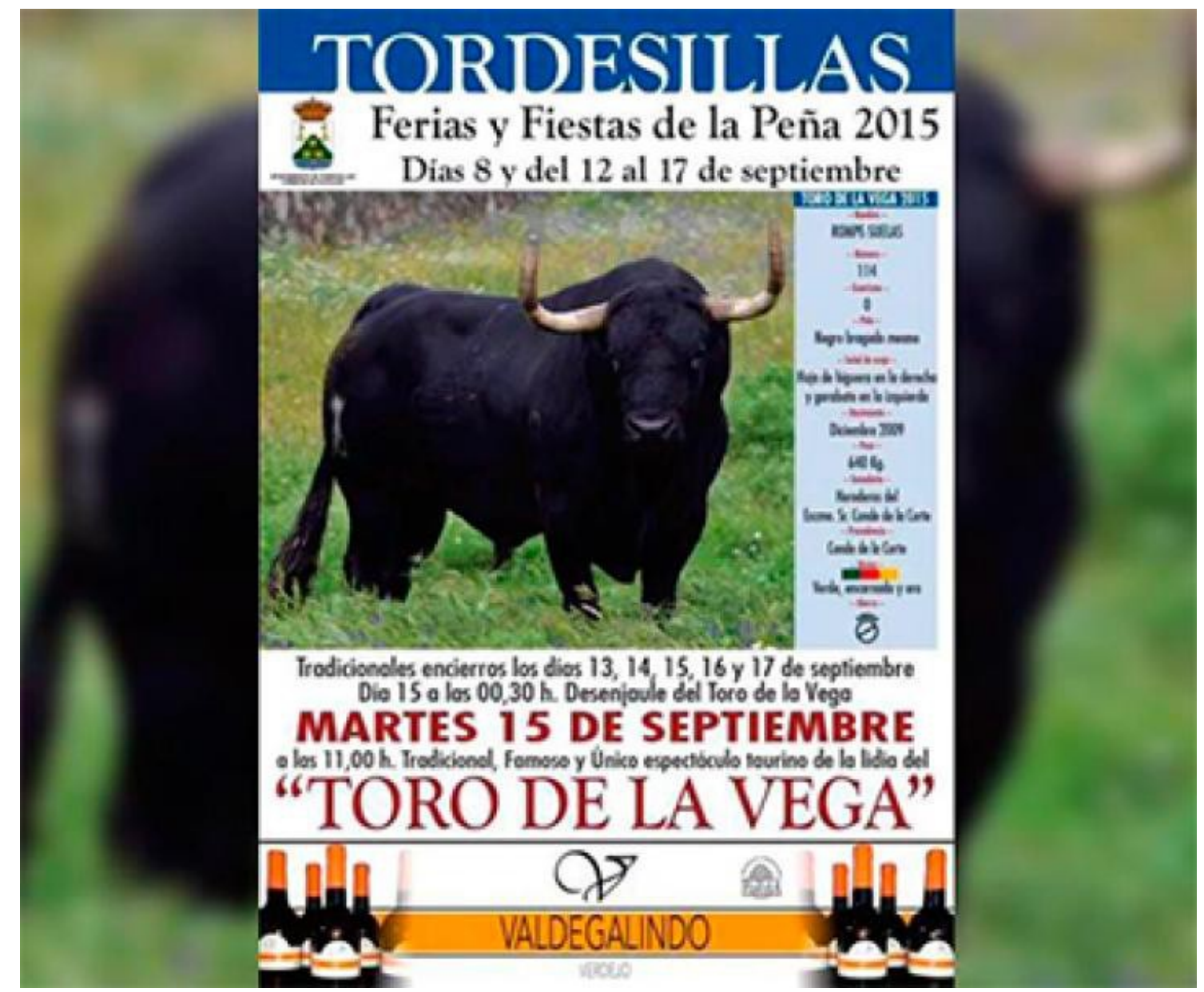

